\title{
AS NECESSIDADES DE EFETUARMOS LEVANTAMENTOS PEDOLÓGICOS DETALHADOS NO BRASIL E DE ESTABELECERMOS AS SÉRIES DE SOLOS.
}

\author{
The need of detailed soil surveys and soil series establishment in Brazil
}

\author{
Igo Fernando Lepsch \\ Professor Visitante junto ao Instituto de Ciências Agrárias da UFMG, em Montes Claros, MG \\ igo.lepsch@yahoo.com.br
}

Artigo recebido em 11/04/2013 e aceito para publicação em 31/07/2013

DOI: 10.12957/tamoios.2013.5665

\section{RESUMO}

Em um levantamento detalhado de solos (escala 1:25.000, ou maior), os pedólogos mapeiam corpos de solo que podem ser considerados como objetos, representados por imagens (chamadas "perfis de solo") as quais podem receber denominações conceituais de acordo com um dado sistema de classificação. Muitos países no início do século passado iniciaram e continuam o mapeamento de seus solos com levantamentos pedológicos detalhados, por meio da identificação das unidades de mapeamento com os nomes das séries de solo. Mais tarde, nos EUA, essas séries também foram conceituadas como unidades taxonômicas. No Brasil, os levantamentos de solos tiveram início priorizando-se mapas de pequena escala, com unidades de mapeamento que receberam nomes de classes de solo de alto nível categórico (grandes grupos) pertencentes a sistemas de classificação de outros países .Hoje, os nomes se referem a táxons do Sistema Brasileiro de Classificação de Solos (SiBCS) - ( subgrupos). Apesar das séries de solo serem consideradas como um dos mais eficientes meios de compartimentação do meio físico, de comunicação e extrapolação de conhecimentos pedológicos, elas ainda não foram devidamente conceituadas no Brasil. Neste artigo é feita uma revisão crítica de literatura sobre esse assunto ressaltando que, para que as séries de solo brasileiras sejam oficialmente identificadas, primeiramente devem ser mapeadas segundo modelos conceituais solo-paisagem, os quais levam em consideração, não só a imagem dos perfis de solo e/ou os conceitos dos táxons do SiBCS, mas principalmente a geomorfologia, estratigrafia e hidrologia.Várias considerações são feitas a esse respeito a fim de se enfatizar a necessidade de mais recursos materiais e humanos para o estabelecimento de um programa brasileiro de levantamento detalhado de solos, bem como o treinamento de novos pedólogos, para que o Brasil venha a ter - a exemplo dos EUA- seu território coberto por mapas de solos em escalas adequadas para aplicações práticas, tais como projetos agrícolas, ambientais e obras de engenharia civil.

Palavras chave: pedologia; classificação de Solos; levantamentos de solos;relação solo-geomorfologia; pedogeomorfologia

In a detailed soil survey (scale 1:25,000 or higher) the field soil scientists map soil bodies, which are considered as objects that are represented by images (soil profiles) which can receive conceptual designations according to a soil classification system. In the beginning of the last century, many countries began mapping their soils with such large scale maps, identifying the mapping units with soil series names which - in the U.S.- were later also conceptualized as taxonomic units. In Brazil the soil surveys began prioritizing small-scale maps with their mapping units receiving designations of classes from high categorical levels (great groups) of soil classification systems of other countries and, more recently, names of taxa (subgroups) of the Brazilian System of Soil Classification (SiBCS). Despite the soil series be universally considered the most efficient ways of partitioning the physical environment, communication and extrapolation of soil knowledge, they have not yet been conceptualized in Brazil. In this article, we critically review the literature on this subject emphasizing that for the first Brazilian soil series to be officially identified they should first be mapped according conceptual soil-landscape models, taking into consideration not only the image of the soil profiles and/or taxa's concepts of the SiBCS but mainly geomorphology, stratigraphy and hydrology. Several considerations are made in this regard, stressing the need for more human and material resource to a Brazilian program of detailed soil survey, as well as the training new soil scientists, so that Brazil can have - like the US-his territory covered by soil maps at suitable scales for practical applications such as agricultural and environmental projects as well as civil engineering works.

Keywords: pedology; soil classification; soil landscape relationships; soil-geomorphology 


\section{INTRODUÇÃO}

Conforme ressaltado por Legros (2006), quando um pedólogo examina e mapeia um solo (e o chama, por exemplo, de Latossolo), ele está distinguindo:

O objeto solo - que é uma entidade natural que é uma entidade natural que existe na natureza.Os locais aproximados da presença desses objetos podem ser mostrados por meio de delineamentos feitos nos mapas;

A imagem solo - que vem a ser o solo tal como o apresentamos a nós mesmos depois de observar seu perfil exposto em uma trincheira ou talude de estrada (no caso, somente as principais feições são observáveis, como na fotografia de um perfil com sua respectiva paisagem);

O conceito de solo - que não tem existência real. É um indivíduo teórico, um táxon (ou uma classe) de um sistema de classificação -o qual representa aquilo que mais se aproxima da imagem - ou perfil representativo- do solo.

Por exemplo: no campo, o pedólogo observa a superfície e o perfil de um corpo de solo existente em uma determinada paisagem (i.e., um objeto). Depois descreve, em um caderno, um perfil que mais representa aquele corpo de solo - declive, cor e textura dos horizontes, etc.- (i. e., uma imagem). Em seguida, identifica esse solo como sendo um Latosssolo Vermelho (i. e. , um conceito). Depois disso, voltando ao campo - olhando a face de uma trincheira -, diz :

"esse perfil é a imagem bi-dimensional de um solo, que representa uma unidade de mapeamento, que foi delineada em um mapa e recebeu um símbolo convencional . O símbolo é $L V$, referente ao nome do subgrupo de uma classe que o sistema brasileiro de classificação de solos (EMBRAPA, 2006) pertencente a grande grupo dos Latossolos Vermelhos cujo perfil foi descrito e que, depois das análises de amostras de seus horizontes terem sido feitas no laboratório, teve sua classificação confirmada como pertencente ao subgrupo dos Latossolos Vermelhos distróficos (LVd).

Nos EUA, o "National Research Conservation Service" do "United States Department of Agriculte"- USDA/NRCS- já mapeou, em detalhe (escala próxima de 1:30.000), os solos de quase todos os municípios do país, identificando as unidades de mapeamento com nomes de séries de solo ( no território norte-americano existem hoje perto de 20.000 séries de solo mapeadas e registradas). Nos EUA, desde 1903, séries de solo foram introduzidas como unidades de mapeamento, e levam nomes regionais (cidades, bairros, rios, etc.), à semelhança dos nomes dados por geólogos às Formações Geológicas . Com o aparecimento da nova taxonomia dos EUA (Soil Survey Staff, 1960 ), as séries de solo, além de unidade de mapeamento, passaram a ser consideradas também como táxons .. Por esta razão ficou estabelecido que o nome de uma série de solo deve ser entendido segundo três contextos ou significados homônimos - (Buol et al. 2011):

a) Como parte do nome de uma unidade de mapeamento presente em áreas representadas numa carta de solos, se a maior parte de seus pédons corresponder à definição de uma classe (taxon), ou forem muito similares a ela (taxadjunt). Por exemplo: "Miami silt loam, 2 to $6 \%$ slopes" (como escrito na legenda de um mapa);

b) Na identificação da imagem de um perfil (ou pédon). Por exemplo, quando alguém, no campo, diante de um perfil de solo, o aponta e exclama: “este é um exemplar da "Miami series!"); 
c) Como uma classe taxonômica (Soil Survey Staff, 1960, 1999) de solo, conceituada dentro de limites de características bem definidas. Por exemplo, a "Miami series" pertence à família dos "Fineloamy, mixed, active, mesic Oxyaquic Hapludalfs" e possui) uma lista de atributos - do perfil e da paisagem - oficialmente registrados e divulgados na internet ${ }^{1}$.

Além dos EUA, vários países (como Argentina e África do Sul) adotam o conceito de séries de solos e têm boa parte de seu território coberto com mapas que as identificam como unidades de mapeamento. Contudo, no Brasil, com exceção de entidades particulares (como o Centro de Tecnologia Canavieira, em São Paulo, que produz mapas para associados produtores de cana de açúcar), pouco tem sido feito para a elaboração de mapas de solos em uma escala apropriada a aplicações diretas por agricultores ou engenheiros civis.

As séries de solo são consideradas como um dos principais meios pelos quais as informações acerca de um solo, (se) bem estudado em determinado lugar, podem ser projetadas para outros similares(o estudo de outros solos similares). A ausência de padronização no levantamentos de solos detalhados, da conceituação e definição das séries de solos brasileiros, bem como a de mapas publicados que mostrem sua distribuição no espaço é uma das maiores preocupações de muitos pedólogos, pesquisadores e estudiosos do solo no Brasil. Este artigo faz a revisão de alguma literatura e defende um) ponto de vista sobre esse assunto, além de complementar um outro recentemente publicado (Lepsch, 2013).

\section{COMO SE INICIARAM OS LEVANTAMENTOS DE SOLOS NO BRASIL}

O programa do Governo Federal para a execução de levantamentos de solos no Brasil começou pouco antes de 1950. Naquele tempo havia uma grande necessidade de inventariar os solos do território brasileiro - a maioria ainda sob vegetação natural de cerrado ou florestas. Apenas algumas pequenas áreas dispunham de levantamentos detalhados, entre as quais destacam-se as do Campus da atual UFFRJ e EMBRAPA AGROBIOLOGIA, onde as séries de solo foram mapeadas em detalhes (Figura 1) por Mendes et al. (1954).

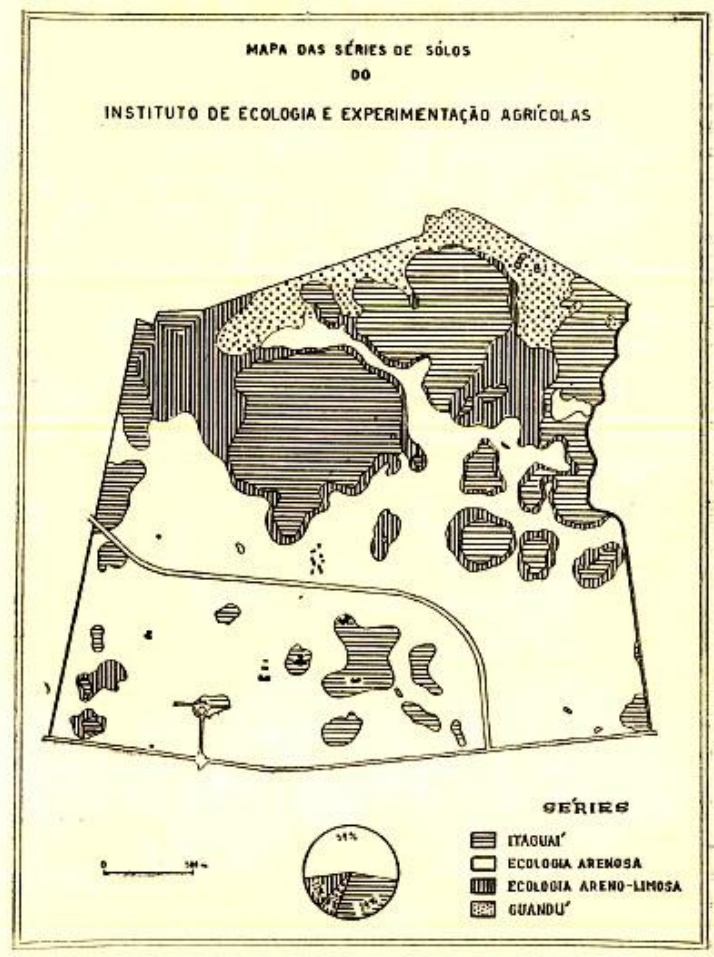

Figura 1 - Fac smile de um dos primeiros mapas pedológicos detalhados publicados no Brasil, mostrando unidades de mapeamento nomeadas como "Séries de Solos" por Mendes et al. (1954).SE séries de solo são consideradas como táxons, Itaguaí, Ecologia, Guandu podem ser considerados como "nomes" e, sua classificação a nível de subgrupo, como "sobrenomes" ( ex.: Argissolo VermelhoAmarelo distrófico). Os nomes das séries facilitam as comunicações a nível regional e os "sobrenomes" ( subgrupos) a nível nacional e internacional. A área corresponde hoje ao Campus da EMBRAPAAGROBIOLOGIA, sediada no município de Seropédica (RJ) cuja área, em 1954, fazia parte do município de Itaguaí (RJ). 
Em 1947 foi criada a Comissão de Solos do Serviço Nacional de Pesquisas Agronômicas (SNPA) do Ministério da Agricultura - a qual deu início aos levantamentos de solos em todo o) Brasil..Os primeiros assessores que vieram treinar os pedólogos de campo que integravam essa Comissão de Solos eram acadêmicos da FAO/UNESCO. Esta entidade, institucionalizada pouco após o término da segunda guerra mundial, tinha iniciado o projeto mapa de solos do mundo; sendo assim havia uma grande necessidade de dados sobre os solos do vasto território brasileiro para ajudar a elaborar o mapa de solos da América do Sul (Beek e Bramão, 1968), o qual compôs a primeira parte desse mapa mundi. Devido a essas circunstâncias, a prioridade era para os mapas de solos do tipo exploratórios e de reconhecimento; - de pequena escala - (1:1.000.000 e 1:500.000, respectivamente) e foram iniciados pela Comissão de Solos (depois transformada na EMBRAPA-SOLOS). Nesses mapas de solos, os nomes das unidades de mapeamento foram obtidos principalmente a partir do antigo, e provisório, sistema de classificação de solos dos Estados Unidos (Baldwin et al. 1938) e das propostas de Kellogg (1948) para nomenclatura de solos tropicais. Nomes como "Podzólico Vermelho-Amarelo", "Podzol", "Solos Aluviais" etc. foram usados, e continuaram a constar dos mapas de solos brasileiros por muitos anos. A partir de 1980, com o lançamento da taxonomia de solos dos EUA (Soil Survey Staff, 1960), desenvolveu-se um sistema brasileiro de classificação de solos (SiBCS) observando-se os princípios similares às abordagens do sistema dos EUA.Vários mapas do tipo reconhecimento foram publicados pelo projeto Radam Brasil e EMBRAPA Solos em várias regiões do Brasil.

O Projeto Radam Brasil operou entre 1970 e 1985. Ele se dedicou a cobrir várias partes do Brasil (especialmente na Bacia Amazônica) usando, como mapa-base, imagens aéreas de radar. A interpretação dessas imagens e o trabalho de campo produziram um importante e abrangente estudo das regiões com textos analíticos e mapas temáticos sobre solos, geologia, geomorfologia, vegetação, uso potencial da terra e capacidade de uso dos recursos naturais renováveis.

Após a conclusão do Projeto Radam Brasil (que produziu mapas de solos na escala 1:1.000.000 em todo o país), o número de pedólogos de campo contratados pelo Governo foi diminuindo. Um programa em nível federal, para uma sistemática de mapeamento município por município, em escalas mais compatíveis com as necessidades de planejamento do uso da terra, ainda não foi estabelecido pelo Governo Federal. Há suspeitas de que os funcionários do governo e ambientalistas, vendo que todos os estados brasileiros já possuíam seu território mapeado em nível de reconhecimento, com mapas coloridos apresentando em suas legendas solos nomeados com os complexos "nomes científicos", decidiram que não mais havia necessidade de continuar o programa de mapeamento de solo nacional para detalhar os mapas em uma escala que pudesse trazer aplicações imediatas nas propriedades agrícolas ou projetos de engenharia civil.

Sob essas circunstâncias, por volta de 1980, os pesquisadores da EMBRAPA-SOLOS, com a ajuda de professores de várias universidades do Brasil, dedicaram-se à preparação do Sistema Brasileiro de Classificação de Solos (SiBCS). Os SiBCS foi lançado em 1999 e, atualmente, está em sua segunda aproximação (EMBRAPA, 2006). Um mapa de solos generalizado, em escala 1:5.000.000, de todo o País com base neste sistema foi publicado (IBGE/EMBRAPA, 2001).

O SiBCS é multicategórico e reconhece 13 classes de solos no nível mais elevado (as ordens dos Argissolos, Cambissolos, Chernossolos, Gleissolos, Latossolos, Luvissolos, Neossolos, Nitossolos, Organossolos, Planossolos, Plintossolos, e Vertissolos). Além dessas ordens, três outras categorias já foram definidas: subordem, grande grupo e subgrupo; definições das famílias estão atualmente sendo estudadas e testadas, mas sem as séries de solo terem sido mapeadas e estabelecidas Vários aspectos da taxonomia americana(Soil Survey Staff, 1960 1999, ) e da FAO/UNESCO ( 1974) foram incorporados. As classes de solos são definidas com base em presença ou ausência de camadas Rev. Tamoios, São Gonçalo (RJ), ano 09, n. 1, pags. 03-15, jan/jun. 2013 
pedogenéticas bem definidas: os chamados horizontes diagnósticos, tais como o "horizonte $\mathrm{B}$ latossólico". Várias outras características quantitativas diagnósticas são consideradas para as subordens e grandes grupos, como saturação por bases, capacidade de troca catiônica, saturação por sódio e algumas características distintivas morfológicas (com ênfase na cor do solo). A maioria dos subgrupos é diferenciada de acordo com o conceito do táxon central (ou típico) para grande grupo e propriedades, indicando propriedades intermediárias para outras categorias, ou solos com características extraordinárias.

Ao contrário da classificação de solos dos EUA (Soil Survey Staff, 1960, 1999), que baseouse em milhares de séries já mapeadas e registradas em 1960, o SiBCS está sendo desenvolvido de forma descendente, i.e., considerando primeiramente os táxons das categorias mais elevadas (ordens e subordens), que estão sendo gradualmente subdividas nas classes das categorias inferiores (grandes grupos, subgrupos e famílias). Dados de perfis, coletados e analisados dos vários levantamentos exploratórios e de reconhecimento foram usados como base do sistema. Para o tão desejado sexto nível - as séries de solo -, Oliveira (2009) apontou vários argumentos sobre a precariedade de condições para estabelecê-las, e gerenciar seu estabelecimento oficial, salientando:

"A rigor, não temos ainda nenhuma série oficialmente estabelecida em nosso país. As poucas supostas séries que por ventura se encontram em levantamentos de solos executados no Brasil, correspondem a classes de solos cujos critérios identificadores, foram estabelecidos sem levar em conta a hierarquia existente no SiBCS elou sem qualquer controle oficial que a tenha considerado como série oficialmente estabelecida isto é, serie que passou por todo aquele "crivo" acima assinalado e referendada por um órgão oficial normalizador".

E ainda:

"Têm-se condições de gerenciar estabelecimento oficial de séries? A preocupante realidade que se apresenta para a pedologia como um todo em nosso país, do ponto de vista de recursos humanos e orçamentário, nos leva à conclusão de que, a permanecer as atuais condições orgânicas dificilmente àquelas instituições terão condições de realizar a contento a tarefa de gerenciar o estabelecimento (validação) de séries em nosso país/estado. Essa realidade nos deixa frustados e inquietos quanto ao desejável ordenamento das classes de solos provenientes de levantamentos detalhados, única forma de evitar, como assinalado, que a criação de séries em, nosso país, vire um incontrolável pandemônio".

Contudo, mesmo inexistindo condições para gerenciar o estabelecimento das séries em nosso país, a atual grande demanda para cartografia pedológica é a de levantamentos detalhados, definidos como os que devem ser executados "em nível de séries" (EMBRAPA, 2006, IBGE, 2007). Por outro lado, os Manuais Técnicos de Levantamento de Solos (IBGE, 2007) e os Manuais de Descrição de Solos no Campo (Santos et al., 2005) não têm instruções adequadas para mapemantos detalhados, porque foram motivados pela necessidade de efetuar levantamentos pedológicos ao nível exploratório e de reconhecimento, nos vários estados brasileiros e em escalas relativamente pequenas.

Por essas razões, os levantamentos pedológicos, em escala maior, que estão sendo executados no Brasil, apresentam múltiplos padrões para apresentação dos mapas e redação dos seus memoriais descritivos. Isso ocorre principalmente pela inexistência de manuais que padronizem esses tipos de levantamentos e de registros oficiais, com definições e símbolos adequados para as unidades de solo que poderiam corresponder às séries de solos. Por exemplo, se na legenda consta um "Argissolo VermelhoAmarelo Distrófico típico textura média/argilosa, pouco profundo, fase pedregosa", ao símbolo oficial do subgrupo - PVAd -, costuma-se adicionar números e/ou letras minúsculas que ficam à escolha do 
operador: por exemplo: PVAd-7p - sendo que, se solo idêntico for mais tarde (e/ou por outro operador) mapeado, a simbologia poderá ser diferente, o que dificultará as comunicações e interpretações. Para contornar essas dificuldades, algumas entidades, como o Centro de Tecnologia Canavieira (CTC), estabeleceram uma legenda padronizada para uso próprio e que vem sendo usada com sucesso, inclusive para fins de interpretações práticas ("Legenda CTC" usada para definir "ambientes de produção" de cana de açúcar em várias regiões do Brasil $^{2}$ ).

Discussões acerca do conceito de séries, como um táxon, já foram iniciadas pelos membros do Comitê Executivo do SiBCS. Contudo, com exceção de poucas áreas ( p. ex.: Figura 1 de Mendes et al., 1954) não existem "séries objetos" (ou "séries mapeadas"). Além disso, como em outros países, presumindo que uma série só poderá ser oficialmente registrada depois de ter uma área mínima mapeada ${ }^{3}$, em adição aos padrões convencionais taxonômicos, é necessário discutir e definir os critérios de delineamento, no campo, das unidades de mapeamento que seriam tomadas como base para definir as futuras séries de solo do Brasil. O mais lógico, seria mapeá-las segundo o paradigma solo-paisagem dos levantamentos de solo descrito por Hudson $(1992)^{4}$.Contudo, isso aparentemente não tem sido feito e poucos pedólogos que mapeiam solos têm conhecimentos básicos de relações solo-geomorfologia e parecem seguir mais o paradigma de taxonomia, cujas desvantagens forma ressaltadas por Swanson (1993).

\section{UMA EXPERIÊNCIA EM RELAÇÕES SOLO-GEOMORFOLOGIA E LEVANTAMENTOS PEDOLÓGICOS DETALHADOS}

Como parte do corpo de pesquisadores da então Seção de Pedologia do Instituto Agronômico de Campinas, SP (IAC),em 1971, engajado nos estudos de pós-graduação em Ciência do Solo na "North Carolina State University", EUA, participamos de cursos de geomorfologia e estratigrafia. Minha tese de doutoramento fez um estudo de caso sobre as relações solo-geomorfologia no Planalto Ocidental do Estado de São Paulo (Lepsch et al., 1977). Retornando ao Brasil, constatamos quão importante eram os estudos de estratigrafia, geomorfologia e hidrologia das nossas paisagens porque, a partir deles seria possível melhor entender a gênese dos solos e estabelecer critérios para mapeamentos pedológicos detalhados. Hoje, acreditamos que, tais conhecimentos ajudaram a melhorar a qualidade dos levantamentos detalhados que efetuamos em fazendas experimentais do IAC (p. ex.: Sakai e Lepsch, 1984). Um resumo sobre esses temas está em Vidal Torrado et al. (2005).

A maior parte do território brasileiro localiza-se em um escudo cristalino bastante estável, sem vulcões, terremotos e desertos. Durante o Pleistoceno, formou-se uma sequência de superfícies geomórficas bastante estáveis e seus depósitos correlativos. De acordo com os geomorfólogos, (p. ex.: Bigarella e Andrade, 1965), as paisagens dessas áreas foram esculpidas durante diferentes condições morfoclimáticas que estão bastante relacionadas com os estágios glaciais e interglaciais que aconteceram nas regiões das altas latitudes; nas baixas latitudes do Brasil, existiram fases úmidas interglaciais (como hoje) e semiáridas nos estágios glaciais.

Durante o início das fases semiáridas, as forças ativas de erosão agiram sobre um regolito muito espesso e intemperizado, alargando os vales e formando várias superfícies de aplainamento que hoje são cortadas por vales mais jovens esculpidos no Holoceno. Esta é uma situação muito diferente da encontrada nas regiões temperadas, onde muitos solos foram formados em depósitos de materiais de idade geológica relativamente jovem e deixados por enormes geleiras continentais apenas há cerca de 10.000 anos. Entre os escudos cristalinos da Guiana e do Brasil Central, o material, do qual muitos dos solos se desenvolveram, foi erodido e redistribuído várias vezes durante alguns episódios de erosão mais intensa, especialmente durante o início das fases de climas semi-áridos coincidentes com uma ou mais das quatro fases glaciais do Pleistoceno. Como resultado, os Rev. Tamoios, São Gonçalo (RJ), ano 09, n. 1, pags. 03-15, jan/jun. 2013 
sedimentos dos depósitos superficiais possuíam pouquíssimos minerais intemperizáveis que contêm importantes nutrientes vegetais (potássio, cálcio, magnésio e fósforo) uma vez que eles foram dissolvidos dos regolitos quando estavam sob as estáveis superfícies geomórficas e/ou durante o transporte (Buol, 2009). Atualmente os solos correlacionados a estas superfícies são os muito intemperizados, ácidos e pouco férteis a agricultura Latossolos (Oxisols) que são formados de material que havia sido expostos a muitos ciclos de desgaste, erosão e deposição (Lepsch e Buol, 1988).

A maior parte dos Latossolos são considerados como sendo solos poligenéticos: quanto mais seus materiais de origem foram retrabalhados pelos agentes erosivos mais intemperizados e $\mathrm{m}$ mais pobres em cátions básicos eles se tornaram. À medida que a sílica e os cátions básicos foram removidos dos regolitos argilas cauliníticas e óxidos de ferro se formaram. A caulinita tornou-se recoberta por filmes óxidos de ferro o que fez que formasse agregados com formato de grânulos, muito pequenos ( entre 1 e $3 \mathrm{~mm}$, por vezes denominados de "pseudo-areias" ( Figura $2^{\mathrm{a}}$ e $3 \mathrm{a}$ ). O resultado dessa pedogênese são solos com poros muito pequenos dentro dos agregados que retém água com tensões muito elevadas e poros grandes entre os micro agregados que fazem com que água percole muito rapidamente .Por isso, os Latossolos, mesmo sendo muito argilosos, são muito permeáveis e tem boas propriedades físicas, favoráveis á agricultura.

(a)

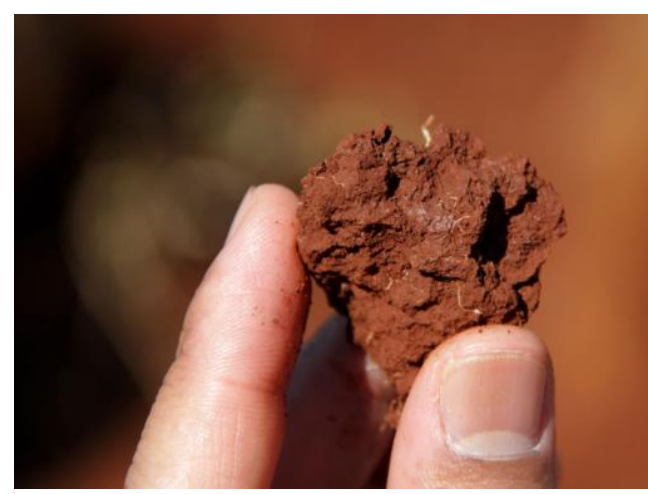

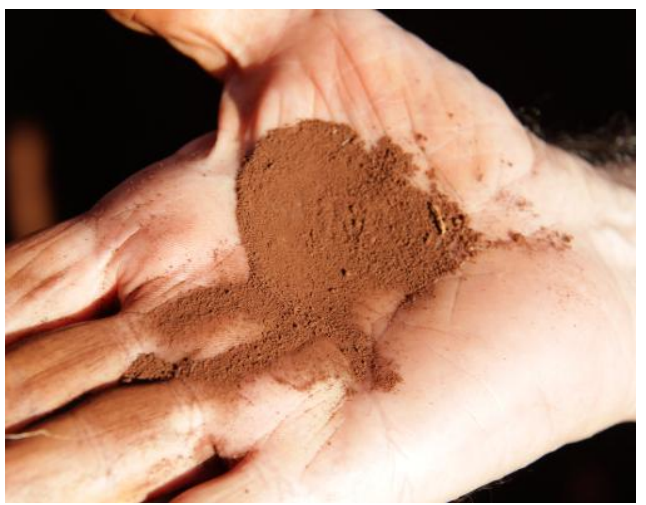

(b)

Figura 2 (a) À esquerda: foto de um agregado subangular, de tamanho médio, do horizonte B de um Argissolo.

Tanto Latossolos e Argissolos costumam ocorrer associados nas paisagens do Brasil tropical úmido; os primeiros nas partes mais elevadas e menos declivosas e os segundos nas encostas mais declivosas. (b) À direita foto dos agregados granulares muito pequenos, por vezes chamados de "pseudo-areias", do horizonte B de um Latossolo. (Fotos: John Kelley).

Em contraste, nos vales superfícies holocênicas, adjacentes as áreas com Latossolos existem solos bem diferentes, pouco espessos e menos intemperizados com maiores quantidades de cátions 
básicos, portanto quimicamente mais férteis; os agregados do horizonte B desses solos são maiores e tem formato subangular ( Figura $2 \mathrm{~b}$ e $3 \mathrm{~b}$ ). Tudo isso ressalta a importância dos estudos de estratigrafia e geomorfologia para delinear as unidades de solo que poderiam servir de base para "batizar" as series de solos brasileiras que poderiam padronizar as legendas dos levantamentos pedológicos detalhados . Para isso há necessidade de treinar novos pedólogos a reconhecer não só a morfologia dos perfis de solos mas também as feições geomórficas, estratigráficas e hidrológicas das paisagens tropicais brasileiras.No entanto não temos conhecimento da existência de cursos de especialização em levantamento de solos que abordem essas disciplinas, tão necessárias para mapear corpos de solo seguindo modelos conceituais solo-paisagem segundo o paradigma descrito por Hudson ( 1992 )

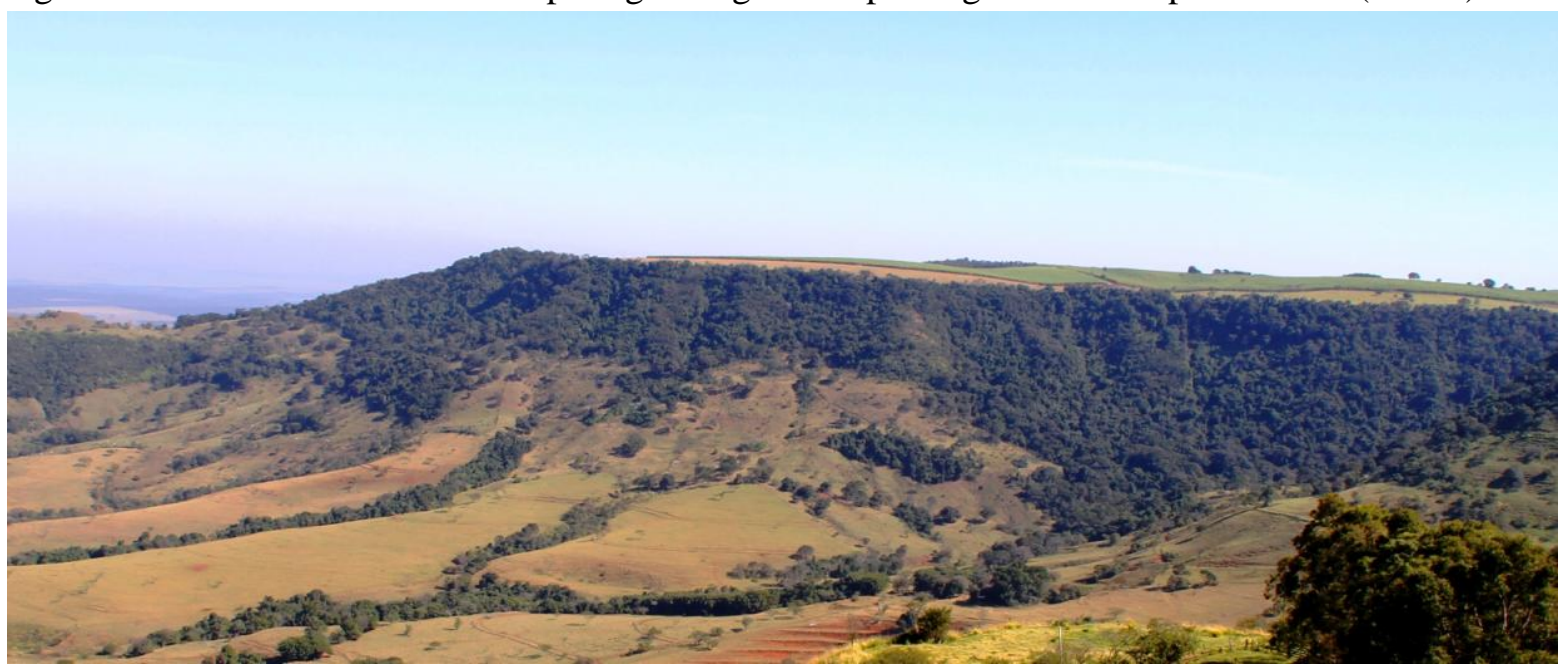

Figura 3 Os solos nessa paisagem das chapadas da região dos Cerrados ainda não estão delineados e "batizados" com nomes de suas séries.No topo da chapada ( superfície geomórfica mais antiga) ocorrem os muito intemperizados e ácidos Latossolos, que originalmente estavam sob vegetação de cerrado; tais solos antes da década de 60 eram considerados como impróprios para agricultura intensiva; hoje são agricultados e responsáveis por boa parte da produção de grãos do Brasil. (Foto: Rodrigo E. M. de Almeida)

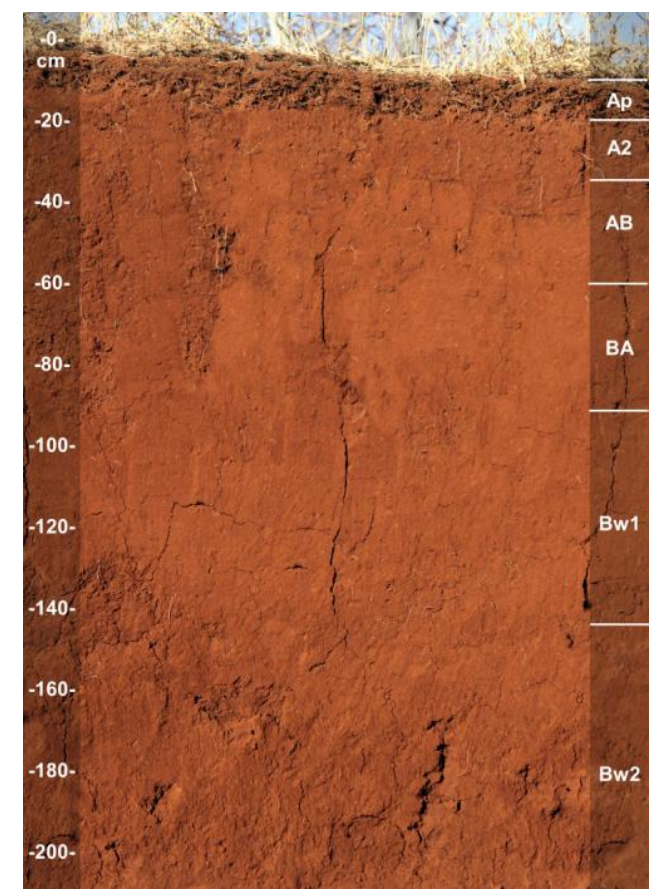

(a) 


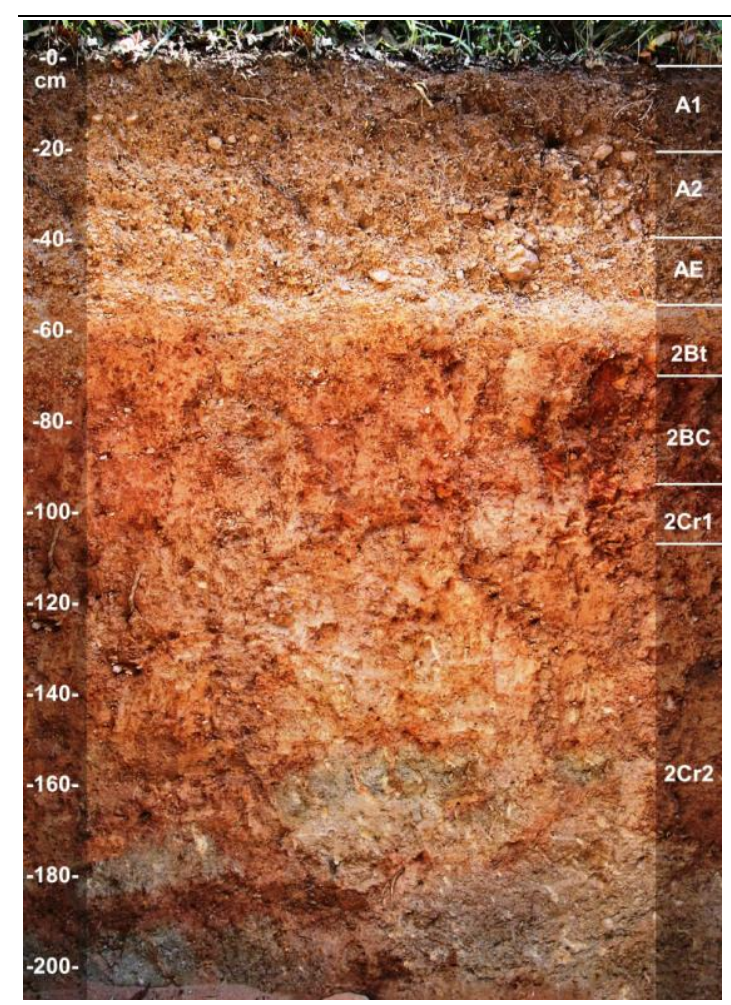

(b)

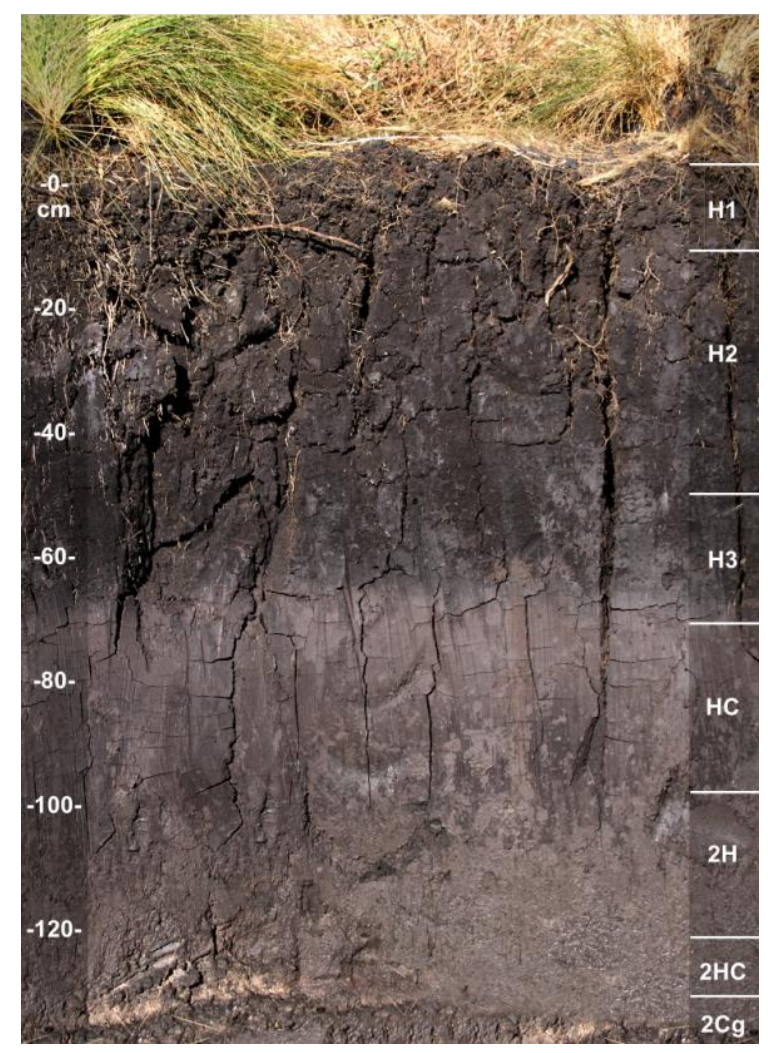

(c)

Figura 4-Três perfis de solos da região dos Cerrados: (a) Latossolo Vermelho, comumente encontrado nos topos quase planos das chapadas (b) Argissolo Vermelho-Amarelo, que pode ser encontrado nos vales que incidem as superfícies mais antigas das chapadas e (c) Organossolo, um solo orgânico, comum nas veredas com vegetação de palmeiras Buritis. (Foto: John Kelley). 
Logo após a inauguração da nova Capital, Brasília, as pesquisas sobre "construção" da fertilidade do solo para agricultura dos Latossolos da região dos Cerrados se intensificaram. Antes, os solos sob cerrado eram considerados como muito problemáticos, poucos acreditavam que eles pudessem ser usados para agricultura intensiva. Muitos diziam mesmo que os Cerrados só serviam “ para perder gado", " criar cobras" ou " fazer longe". De fato os campos cerrados eram usados somente como pastagens extensivas e suas gramíneas pastejadas pelo gado eram tão pobres em cálcio e fósforo ( tal como os solos) que muitos animais quebravam seus ossos mesmo em pequenas quedas.Hoje essa situação muito mudou conforme relatado por Buol ( 2009)

"A moderna ciência de solo, liderada pelas suas pesquisas no Brasil, tem possibilitado a utilização de vastas áreas de solos, durante muito tempo não cultivados por serem avaliados como inaptos para uma intensiva produção de alimentos. Hoje, ao contrário, constata-se que essas terras são altamente produtivas para a agricultura. Estas pesquisas vêm mostrando que alguns atributos naturais destes solos, como acidez, baixos teores de matéria orgânica, baixa capacidade de troca de cátions, além de altos teores de óxidos de ferro elou de alumínio - considerados como obstáculos à produção de boas colheitas em latitudes tropicais - podem ser superados. Com a continuação do desenvolvimento das infra-estruturas necessárias para alavancar ainda mais a agricultura comercial, o Brasil tem potencial para, em breve, liderar o mundo no que tange ao fornecimento de alimentos para as crescentes populações humanas “

No ano agrícola 2012/13 o Brasil produziu cerca de 180 milhões de toneladas de grãos (incluindo 84 milhões de toneladas de soja) a maior parte cultivados nos Latossolos das chapadas do Brasil Central. Isto coloca o país na posição do primeiro "gigante agrícola" tropical e o primeiro a desafiar o domínio dos cinco maiores exportadores de alimentos (Estados Unidos, Canadá, Austrália, Argentina e União Européia). Tal produção recorde esta sendo colhida e exportada mesmo sem o pleno desenvolvimento das necessárias infra-estrutura ( boas estradas, silos etc.) e mapas detalhados de solos; com estes últimos os agricultores poderiam decidir melhor onde - nas terras ocupadas pela vegetação de cerrado - é mais conveniente, sob ponto de vista ambiental e de produtividade agrícola, desmatar e cultivar.

\section{A NECESSIDADE DE BRASIL DEFINIR SUAS SÉRIES DE SOLOS}

O Sistema Brasileiro de Classificação de Solos (EMBRAPA, 2006) foi uma grande conquista e muito tem contribuído para o avanço do conhecimento do nossos solos. Este sistema categoriza todos solos do Brasil baseando-se em atributos bem definidos dos perfis de solo bom como características físicas e químicas importantes para o uso das terras.Contudo, as definições das classes já estabelecidas dos níveis categóricos mais elevados - ordem, subordem, grande grupo e subgrupos consideram os solos como simples pontos (perfis) de solo na paisagem; somente uns poucos critérios sobre características do relevo dos solos são consideradas.Este sistema de classificação de solos como muitos outros de outros países- ajuda a organizar nosso conhecimento acerca de nossos solos de forma que as propriedades dos objetos classificados possam ser lembradas e suas inter-relações melhor entendidas. Contudo, uma vez que nós não temos definidas as categorias que mais de perto corresponderiam aos corpos de solos - as series de solo e suas fases - ele não é de muita utilidade para a execução dos levantamentos mais detalhados.Por outro lado com a ênfase em características dos perfis do solo muitos pedólogos tendem a ter uma "visão afunilada" das terras considerando muito mais os perfis expostos em trincheiras abertas em um único local do corpo do solo sem tentar integrálo na paisagem como um todo. Em outras palavras a atenção maior tem sido na IMAGEM (perfil do solo) e CONCEITO ( classificação) deixando o OBJETO ( corpo de solo) em segundo plano. 
Acreditamos que existe uma grande necessidade de treinar pedólogos de campo, incluindo conhecimentos de geomorfologia, estratigrafia e hidrologia para que possamos produzir bons mapas detalhados de solos com relatórios incluindo recomendações para aplicações práticas a diversas finalidades (obras de engenharia civil inclusive). Para isso serão necessários acréscimos de recursos de verbas e pessoal para Instituições Governamentais como a EMBRAPA SOLOS.

Nos EUA, as verbas e políticas nacionais para acelerar - em nível nacional- o programa de levantamento de solos surgiram quando o famoso Dr. Hugh H. Bennett ( cognominado o "Pai da Conservação do Solo"), durante a Grande Depressão do início do século passado, que coincidiu com os anos em que houve grandes erosões eólicas no meio oeste americano ( os "dust blow years") . O Dr. Bennet, em 1934, conseguiu convencer os Congressistas americanos que uma das maiores causas da depressão econômica era a erosão dos solos; desta forma convenceu o seu Governo a liberar recursos para montar o "Soil Erosion Service" que, mais tarde, se tornou parte do "National Resource Conservation Service" ( NRCS do USDA). O NRCS vem, desde os anos 30 do,elaborando mapas detalhados de solos, município por município, estando agora quase todo os EUA coberto por esses mapas. Tais mapas além da distribuição espacial dos solos são acompanhados de relatórios com recomendações práticas sobre uso dos solos para agricultura, florestas, obras de engenharia civil etc.

Considerando que a EMBRAPA-SOLOS agora tem apenas algumas dezenas de pedólogos de campo, e que seria altamente desejável mapear os 8,5 milhões de $\mathrm{km}^{2}$ do nosso território com asinfelizmente ainda não definidas - " séries de solo brasileiras", sentimos uma necessidade urgente de alguém como o Dr. Bennett (esperamos que sem os catastrófico eventos como a Grande Depressão e as nuvens de poeira provocada pela erosão eólica nos EUA durante os anos 30) para convencer o nosso Governo a adotar políticas desenvolvimentistas liberando fundos suficientes para iniciar um programa de treinamento de pedólogos de campo e levantamentos detalhados de solo em nosso país.

AGRADECIMENTOS: A John Kelley ( USDA/NRCS retired state soil scientist), a Profa. Ivana Q. de Andrade pela revisão do manuscrito e aos participantes do Grupo de Discussão sobre Levantamentos de Solos ( http://groups.google.com/group/soil-mapping/about) pelas muitas sugestões e idéias que muito ajudaram a compor este artigo.

\section{NOTAS}

${ }^{1}$ Descrições da "Miami soil series" estão disponíveis no portal: http://www2.ftw.nrcs.usda.gov/ osd/dat/M/MIAMI.html.

${ }^{2}$ Alguns detalhes sobre a "legenda CTC" e conceito de "ambientes de produção para cana de açúcar" podem ser vistos no portal: http://www.riosvivos.org.br/dowloads/soloeambiente_donzelli.pdfb.

${ }^{3}$ O "National Resource Conservation Service" do USDA preconiza que uma nova série só poderá ser reconhecida e registrada depois que um "field soil scientist" demonstrar que pelos menos 1.000 ha da mesma possam ser mapeados. Tais séries, além de ser a categoria mais baixa do Sistema Americano de Classificação de Solos, são os mais comuns termos de referências para dar nome às unidades de mapeamento dos levantamentos de solos dos EUA.

${ }^{4}$ Hudson (1992) esboçou a aplicação do conceito de catena (Milne,1936) e da equação dos fatores de formação do solo (Jenny, 1941) para o levantamento de solos como um modelo geral de percepção e mapeamento de solos em uma ordem geográfica. Ele também resumiu o paradigma solo-paisagem que 
tem orientado as pesquisas de campo e levantamentos detalhados de solos nos Estados Unidos por quase um século

${ }^{5}$ Por exemplo o mapa e relatório do levantamento pedológico detalhado do município de Madison, no Estado da Carolina do Norte, com interpretações para várias finalidades práticas, pode ser obtido no portal: http://soildatamart.nrcs.usda.gov/manuscripts/NC115/0/Madison_NC.pdf

\section{REFERÊNCIAS}

BALDWIN, M.; KELLOGG, C. E. ; THORP, J. Soil classification. In: Soils and Men. Washington, D.C.: United States Department of Agriculture,. p.707-1001, 1938 (USDA Yearbook of Agriculture). BEEK, K.J.; BRAMÃO, L.D. Soil map of South America 1:5.000.000. Rome: FAO/Unesco, 1968. 530p. 1968 (FAO. World Soil Resources Reports, 34).

BIGARELLA, J.J.; ANDRADE, J.O. Contribution to the studies of the Brazilian Quaternary. Sp. Paper. Geol. Soc. Am., 64:433-451, 1965.

BUOL, S. W. Soils and agriculture in central-west and north Brazil. Scientia Agricola. 66:(5)697-707, 2009

BUOL, S. W., SOUTHARD R. J., GRAHAM R.C.; MCDANIEL P. A. Soil Genesis and Classification. Iowa State Press a Blackwell Publishing Co. (6a Ed.), 2011.

EMBRAPA. CENTRO NACIONAL DE PESQUISA DE SOLOS. Sistema Brasileiro de Classificação de Solos. 2. ed. Brasília: Embrapa Produção de Informação; Rio de Janeiro: Embrapa Solos, 2006. 306 p.

FAO/UNESCO Soil map of the word: 1:5,000,000 legend. Paris, UNESCO. 1974161

HUDSON, B.D., The soil survey as paradigm-based science. Soil Science Society of America Journal, 56, pp. 836-841,1992.

IBGE/EMBRAPA. Mapa de Solos do Brasil (1:5,000,000). Rio de Janeiro: Instituto Brasileiro de Geografia e Estatística, 2001. Disponível em: http://mapas.ibge.gov.br/solos/viewer.htm

IBGE. COORDENAÇÃO DE RECURSOS NATURAIS E ESTUDOS AMBIENTAIS. Manual técnico de pedologia. 2. ed. Rio de Janeiro: IBGE, 2007. 323 p. (IBGE. Manuais Técnicos em Geociências) disponível em http://www.ibge.gov.br/home/geociencias/ recursosnaturais/ sistematizacao/manual pedologia.shtm.

JENNY , H. Factors of Soil Formation. Mc Grall-Hill, Nova Yorque, 1941

KELLOG, C. E. Preliminary suggestions for the classification and nomenclature of great soil groups in the tropical and equatorial regions. Commonw. Bur. Soil Sci. Tech. Comm., 46: 76-85, 1949.

LEPSCH, I.F.;BUOL, S.W.; DANIELS, R.B. Soil landscape relationships in the occidental plateau of São Paulo, Brazil: I. Geomorphic surfaces and soil mapping units. Soil Sci. Soc. Am. J., 41: 104-109, 1977.

LEPSCH, I. F.; BUOL, S.W. 1988 Oxisol-landscape relationships in Brazil In: INTERNATIONAL SOIL CLASSIFICATION WORKSHOP, 1986, Rio de Janeiro, R J. Proceedings... Classification, characterization and utilization of Oxisols. Rio de Janeiro: EMBRAPA-SNLCS/SMSS/USDASCS/UPR, 1988. 285p. (Part 1: Papers. p.174-189)

LEGROS, J. P Mapping of the Soil. Science Publishers. N. Jersey, 2006. 
MENDES, W. P. de O.; CRUZ LEMOS, R. C.; LEMOS, L. G. de ; CARVALHO, R. J. Contribuição ao mapeamento em séries dos solos do Município de Itaguaí. Rio de Janeiro: CNEPA: IEAE, 1954. 53 p. Disponível em: http://library.wur.nl/isric/fulltext/isricu_i22664_001.pdf

MILNE G. Some suggested units for soil classification and mapping, particularly for East African soils. Soil Res. ( Berlin) 4: 183-198, 1935

OLIVEIRA, J. B. de As séries e o novo Sistema Brasileiro de Classificação de Solos. Tem-se condições de gerenciar o seu estabelecimento? Blog do SiBCS, 2009. Disponível em http://www.cnps.embrapa.br/sibcs (Acessado em 10/06/2010).

SOIL SURVEY STAFF Soil Taxonomy: A basic system of soil classification of making and interpreting soil surveys.1st ed. . Washington, USDA-Natural Resources Conservation Service,1975. 869p. (USDA. Agriculture Handbook, 436)

SWANSON, D. K.Comments on "The soil survey as paradigm-based science." Soil Science Society America Journal 57:1164, 1993

SANTOS, R. D. dos ; LEMOS, R. C. DE ; SANTOS, H. G. dos ; KER, J. C. ; ANJOS , L. H. C. dos Manual de Descrição e Coleta de Solo no Campo. 5. ed. Viçosa, MG: Editora Folha de Viçosa Ltda., 2005. $100 \mathrm{p}$.

SAKAI, E.; LEPSCH, I. F. Levantamento pedológico detalhado da Estação Experimental de Pariquera Açu. Boletim Técnico. Instituto Agronômico de Campinas, Campinas, SP, n. 831984. 56p. SOIL SURVEY STAFF Soil taxonomy: A basic system of soil classification of making and interpreting soil surveys. 2.ed. Washington, USDA-Natural Resources Conservation Service, 1999. 869p. (USDA. Hariculture Handbook, 436) ftp://ftpfc.sc.egov.usda.gov/NSSC/Soil_Taxonomy/tax.pdf

SOIL SURVEY STAFF Soil Classification, a Comprehensive System $-7^{\text {th }}$ Approximation. USDA. U.S. Government Printing Office, Washington, DC, 1960.

VIDAL-TORRADO, P. ; LEPSCH, I. F. ; CASTRO, S. S. Conceitos e Aplicações das Relações Pedologia Geomorfologia em Regiões Tropicais Úmidas. In: P. Vidal-Torrado; Luiz R. Ferraciu; M. Cooper; Elke J. Cardoso; Luiz I. Prochonow. (Org.). Tópicos em Ciência do Solo. Viçosa: Sociedade Brasileira de Ciência do Solo, 2005, v. IV, p. 145-192. 